PROCESS PARAMETERS AFFECTING THE SUPERCRITICAL FLUID EXTRACTION- A REVIEW

\author{
D.SRINIVAS ${ }^{1}$, N.HARISH ${ }^{2}$, K.ANIL KUMAR ${ }^{3}$ \& SIVALA KUMAR ${ }^{4}$ \\ ${ }^{1,2,3}$ P G Student, Professor at College of Agricultural Engineering, Bapatla, Andhra Pradesh, India \\ ${ }^{4}$ Professor at College of Agricultural Engineering, Bapatla, Andhra Pradesh, India
}

Solvent extraction has major applications in extraction of vegetable oils, nuclear processing, production of fine organic compounds, processing of perfumes and other industries. But, now days, use of this method is dropping due to the solvents cost, chemical deposits and legal issues with disposal of waste after use. All these demerits are overcome by supercritical fluid extraction process. This extraction method is affected by several process parameters; those are reviewed in this paper.

KEYWORDS: Solvents, Supercritical Fluid, Carbon Dioxide, Pressure, Temperature \& Extraction Time
\end{abstract}

Received: Jun 24, 2017; Accepted: Jul 13, 2017; Published: Aug 01 2017; Paper Id.: IJASRAUG201780

\title{
INTRODUCTION
}

Solvent extraction is a technique, applied to separate compounds based on their relative solubilities in two different immiscible liquids. It is also known as liquid-liquid extraction. It has major applications in extraction of vegetable oils, nuclear processing, production of fine organic compounds, processing of perfumes and other industries. In spite of the fact that the strategy can be utilized for extraction of an extensive variety of non volatile or semi volatile species utilizing just routine research facility, its utilization is diminishing as a rule, since solvents of the required immaculateness have a tendency to be costly, and can likewise cause issues with legitimate transfer after utilization. Reducing the negative ecological impacts of solvents, eliminating chemical compound deposits, lower energy requirements, better quality and safety in food processes has been a main thrust in utilizing supercritical liquids, particularly carbon dioxide as extraction solvent $[3,4]$.

In 1993, supercritical carbon dioxide was utilized for extraction of pepper oil [5] and from that point on, it has been utilized as a part of numerous extraction procedures, for example, caffeine from coffee [6], cholesterol from beef and egg [7], basic oils from basil [8] and cocoa margarine from cocoa nibs [9]. In 1995, Hung et al. [10] could extricate cholesterol with 70 percent yield. Later in 2001, Wu, et al. [11] accomplished even a superior extraction yield by optimizing temperature and pressure $\left(55^{\circ} \mathrm{C}\right.$ and $\left.36 \mathrm{MPa}\right)$. Despite the fact that the most widely accepted supercritical liquid is pure or adjusted carbon dioxide due to its low critical temperature, nonharmfulness, inertness and low cost, nevertheless in some cases such as polar ingredients other alternative compounds, for example, nitrous oxide, ethane and water, have critical properties that can give better consequences of extraction yield. D.A Saldana et al. [12] found that supercritical carbon dioxide with no co-solvent couldn't remove theobromine from cocoa seed in an appropriate yield. Sh. Li, S. Hartland [13] demonstrated that it is hard to remove either xanthines or cocoa margarine from cocoa nibs with $\mathrm{CO}$ alone. Be that as it may, the expansion of 
polar co-solvent ethanol incredibly upgrades their solubility. R. S. Mohamed et al. [14] demonstrated that utilizing ethanol or isopropanol as co-solvent with supercritical carbon dioxide will increase the yield of extraction. Other n-alkanols, additionally have been utilized as co-solvent with supercritical carbon dioxide $[15,16]$ on account of their polar properties.

In this review, we summarize the supercritical fluid extraction process and effect of different parameters on the extraction.

\section{SUPERCRITICAL FLUID EXTRACTION PROCESS}

This arrangement must consist a pump for the $\mathrm{CO}_{2}$, a pressure cell and gathering vessel. The fluid is heated to supercritical conditions by pumping to a heating zone. It at that point goes into the extraction vessel, where it quickly diffuses into the solid matrix and dissolves the material to be removed. The dissolved material is cleared from the extraction cell into a separator at lower pressure, and the extricated material settles out. The $\mathrm{CO}_{2}$ would then be able to be cooled, recompressed and reused, or released to air.

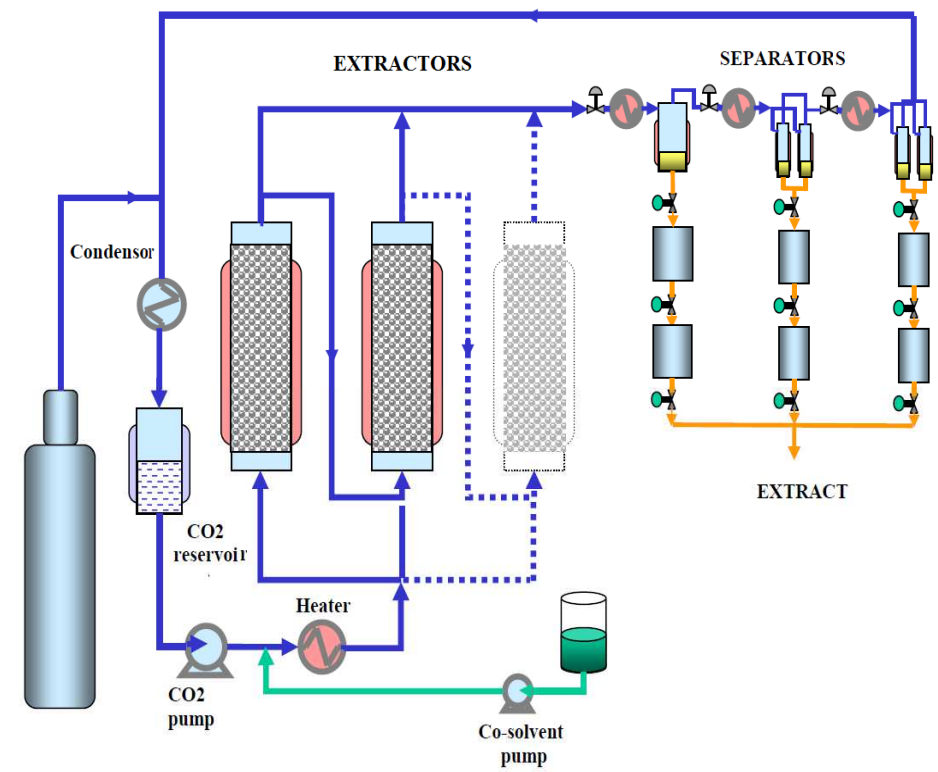

Figure 1: SCFE Processing Unit

\section{PARAMETERS AFFECTING THE SUPERCRITICAL FLUID EXTRACTION- REVIEW}

In spite of the fact that the choice of the supercritical solvent to be utilized might be imagined as the mostimpacting parameter in the extraction, there are various critical parameters that will altogether influence the extraction process. These parameters are described here.

\section{Effect of Particle Size}

T.J. Tan et al. [9] had done a research on extraction of oil from whole cocoa beans using $\mathrm{SC}-\mathrm{CO}_{2}$ as solvent. They observed that there was a slow increasing trend in extraction efficiency, when using particles with smaller size. It is likely that the oil is caught inside the cell walls and does not come into contact with the supercritical solvent. Whenever pulverized, some cell walls are cracked and subsequently, the oil inside them ends up noticeably accessible for extraction. The effect of particle size in three unique temperatures (15 MPa and 6 hours extraction time) is appeared in Table 1. 
Table 1: Effect of Particle Size on Extraction Efficiency for Three different Temperatures (P=15 MPa, 6 Hrs Extraction Time) Using Pure CO, as Supercritical Solvent

\begin{tabular}{|l|c|c|c|c|c|}
\hline \multicolumn{1}{|c|}{ Partical Size (mm) } & $\begin{array}{c}\text { Uncrushed } \\
\text { Particles }\end{array}$ & $\mathbf{2 - 4}$ & $\mathbf{1 - 1 . 4}$ & $\mathbf{0 . 5}-\mathbf{1}$ & $\mathbf{0 . 2 5 - 0 . 5}$ \\
\cline { 2 - 6 } $\begin{array}{l}\text { Efficiency (\%) } \\
\mathrm{T}=30^{\circ} \mathrm{c} \\
\mathrm{T}=40^{\circ} \mathrm{c} \\
\mathrm{T}=50^{\circ} \mathrm{c}\end{array}$ & 0 & 2.3 & 2.7 & 2.85 & 2.9 \\
\cline { 2 - 6 } & 0 & 2.5 & 2.8 & 3 & 3 \\
\hline
\end{tabular}

Li et al. [17] investigated $\mathrm{SC}-\mathrm{CO}_{2}$ extraction of black pepper at 16-26 $\mathrm{MPa}$, temperature of $308-323 \mathrm{~K}$, and solvent flow rate from $0.2-0.4 \mathrm{~m}^{3} / \mathrm{h}$, and diameter of ground material of 20-50 meshes. They concluded that the extraction rate increased with increasing particle size, due to intraparticle diffusion resistance was smaller for smaller particle size, because of shorter diffusion path. Essential oil obtained by $\mathrm{SC}-\mathrm{CO}_{2}$ extraction had higher levels of sesquiterpenes and monoterpenes.

\section{Effect of Pressure}

Increases in extraction pressure increase yield in lycopene recovery (Nobre et al. 2009, Yi et al. 2009; Lenucci et al. 2010, Huang et al. 2008, Rozzi et al. 2002, Baysal et al. 2000), while applications employing pressure values ranging between 200 and 450 bar produce optimum results depending on other process parameters, especially extraction temperature, and/or type and features of product. Optimum pressure parameter in lycopene recovery through SFE method are generally reported between 300 and 400 bar; however, especially 400 bar was set out as the optimum process parameter with different extraction temperatures ranging between $40^{\circ} \mathrm{C}$ and $100^{\circ} \mathrm{C}$ (Ciurlia et al. 2009, Topal et al. 2006, Huang et al. 2008, Yi et al. 2009, Saldana et al. 2010).

Solubility of oil increased with increase of the pressure, because of the solvent density increase. It was possible to identify the constant extraction rate period in the extraction curves as well as the falling and diffusion rate period. When the yield of the $\mathrm{SC}-\mathrm{CO}_{2}$ extraction was compared with that of steam distillation, it can be concluded that SFE was an efficient process for black pepper oil extraction. Perakis et al. [4] showed the results of the $\mathrm{SC}-\mathrm{CO}_{2}$ extraction of ground black pepper, they examined effect of process parameters, namely pressure $(9,10,15 \mathrm{MPa})$, temperature $(313,323 \mathrm{~K})$ on extraction rate.

Salajegheh et al. (2013) investigated $\mathrm{SC}-\mathrm{CO}_{2}$ extraction of Cocoa Butter from Cocoa seed, keeping other conditions constant $\left(40^{\circ} \mathrm{C}\right.$ temperature, 6 hours extraction time and particles smaller than $\left.1 \mathrm{~mm}\right)$, the effect of pressure was investigated. The results are reflected in, as one might expect, higher pressures result in higher density of solvent which increases the solvent power, and therefore an increasing trend of higher extraction efficiency is observed. The highest efficiency observed is at $20 \mathrm{MPa}$, which is the pressure limit for the equipment used in these experiments.

Li et al. [17] investigated SC- $\mathrm{CO}_{2}$ extraction of black pepper at 16-26 MPa, temperature of 308-323 K, solvent flow rate from $0.2-0.4 \mathrm{~m}^{3} / \mathrm{h}$, and diameter of ground material of 20-50 meshes. They concluded that the extraction rate was higher at higher pressure, because of the fact that at constant temperature, the density of the solvent increases with pressure increase and the vapor pressure of the solute decrease with pressure increase.

\section{Effect of Temperature}

The temperature used in extraction process varies within a wide range like $50-110^{\circ} \mathrm{C}$ is considered as optimum. 
However, most frequently reported value is $80^{\circ} \mathrm{C}$ as optimum (Egydio et al. 2010, Vagi et al. 2007, Sabio et al. 2003, Cadoni et al. 2000). Number of studies indicating temperature esteems over $80^{\circ} \mathrm{C}$ as an optimum is limited (Yi et al. 2009, Topal et al. 2006, Rozzi et al. 2002, Ollanketo et al. 2001). No relation could be found between this value and characteristics of material.

Salajegheh et al. (2013) investigated SC- $\mathrm{CO}_{2}$ extraction of Cocoa Butter from Cocoa seed, two temperature series from $30^{\circ} \mathrm{C}$ to $55^{\circ} \mathrm{C}$ (at pressures of $15 \mathrm{MPa}$ and $20 \mathrm{MPa}$ ) were conducted, both with 6 hour extraction time and particle size of less than $1 \mathrm{~mm}$ diameter. The results showed that an increase in solubility in higher temperatures, the efficiency of extraction rises slowly as the temperature increases.

Li et al. [17] investigated SC- $\mathrm{CO}_{2}$ extraction of black pepper at 16-26 MPa, temperature of 308-323 K, and solvent flow rate from $0.2-0.4 \mathrm{~m}^{3} / \mathrm{h}$, and diameter of ground material of 20-50 meshes. They concluded that the extraction rate increases with an increase in temperature at $25 \mathrm{MPa}$ and decreases with an increase in temperature at $10 \mathrm{MPa}$. This behavior could be explained by appearing so call "cross-over" pressure between this two values of pressure, which means that than exists two competing effects of reduction in solvent density and the increase in solute vapor pressure with increase in temperature. The fact is that at lower pressure, the change of the solvent density is more efficient than that of solute vapor pressure, as extraction rate increases with decrease in temperature. However, at higher pressure (25 MPa) the extraction rate is dependent on the solute vapor pressure and it increase with an increase in temperature. The optimal process condition of the supercritical fluid extraction for pepper oil was at 22-26 MPa, $318 \mathrm{~K}$, and $0.3-0.4 \mathrm{~m}^{3} / \mathrm{h}$.

Shi et al. [18] utilized different temperatures from 40 to $70{ }^{\circ} \mathrm{C}$ in the $\mathrm{SC}-\mathrm{CO}_{2}$ extraction of carotenoids from pumpkin. They found that carotenoid yield increased with increasing temperature. The highest extraction yield (6.1 $\mathrm{mg} / 100 \mathrm{~g}$ matrix d.m.) was obtained at $70{ }^{\circ} \mathrm{C}$ and $35 \mathrm{MPa}$. At the point, when the extraction temperature was raised from 40 to $70{ }^{\circ} \mathrm{C}$, the $(9+13)-\mathrm{Z}$ - $\beta$-carotene isomers increased considerably from $10.3 \%$ to $12.7 \%$ at $25 \mathrm{MPa}$ and from $8.0 \%-12.5 \%$ at $35 \mathrm{MPa}$. What's more, when the extraction temperature was increased from 50 to $80{ }^{\circ} \mathrm{C}$ at a constant pressure of $25 \mathrm{MPa}$, there was a decrease in carotenoid yield from 132.2 to $44.6 \mathrm{mg} / 100 \mathrm{~g} \mathrm{~d} . \mathrm{m}$. also, the ratios of $\mathrm{Z}$ - $\beta$-carotene/ carotenoids increased from $13.7 \%$ to $24.5 \%$.

\section{Effect of Extraction Time}

Salajegheh et al. (2013) investigated SC- $\mathrm{CO}_{2}$ extraction of Cocoa Butter from Cocoa Seed, the result of varying extraction times at $20 \mathrm{MPa}$ and $50^{\circ} \mathrm{C}$ increases extraction efficiency significantly up to 6 hours, and then remains fairly unchanged up to 8 hours because the system reaches the equilibrium state.

\section{Use of Ethanol as Co-Solvent}

Ethanol is the commonly used co-solvent with the usage rate ranging between $5.0 \%$ and $16.0 \%$ (Saldana et al. 2010, Shi et al. 2009a, Kassama et al. 2008, Baysal et al. 2000) for the effectiveness of extraction, while organic solvents like chloroform (Cadoni et al. 2000), tetrahydrofluran (Ciurlia et al. 2009), and acetone (Ollanketo et al. 2001) as well as vegetable oils like olive oil (Shi et al. 2009a), canola oil (Saldana et al. 2010) and hazelnut oil (Vassapollo et al. 2004) were also employed for this purpose. An increase in the ratio of modifier or co-solvent increases yield (Shi et al. 2009a). For the usage as modifier, various optimum ratios and types were reported like 5.0\% ethanol (Baysal et al. 2000), 10.0\% vegetable oil (Vasapollo et al. 2004), 5.0\% olive oil + 5.0\% ethanol (Shi et al. 2009a) and 14.0\% ethanol (Kassama et al. 2008). It is believed that the use of vegetable oil (for example hazelnut oil) contributes to solubility of lycopene in solvent 
(Ciurlia et al. 2009). Furthermore, it was reported that there is a synergic effect between concentration of modifier and extraction temperature, while it does exist between pressure and modifier concentration (Kassama et al. 2008); however, there are researchers reporting that the use of a modifier like ethanol, water, and olive oil increases lycopene yield independently from variations in temperature and pressure (Shi et al. 2009a).

Salajegheh et al. (2013) investigated SC- $\mathrm{CO}_{2}$ extraction of Cocoa Butter from Cocoa seed, ethanol was chosen as a co-solvent for our extractions because of its "Generally Regarded as Safe (GRAS)" status in The Food and Drug Administration of USA (FDA), polar nature and the significant impact that it has on the polarity of $\mathrm{CO}_{2}$ solutions. It is readily available in food grade and therefore there are no concerns regarding residual amounts left in the cocoa butter. Using the best conditions found for pure supercritical carbon dioxide, i.e. particle size of less than $1 \mathrm{~mm}$, extraction time of 8 hours, pressure of $20 \mathrm{MPa}$ and temperature of $50^{\circ} \mathrm{C}$, we carried out a series of extractions using ethanol as co solvent in various concentrations. There was Single pass extraction efficiency rises to $15.8 \%$ at $10 \%$ ethanol concentration. This is an almost $200 \%$ improvement on the results obtained using pure $\mathrm{CO}_{2}$ as the extraction solvent. Another series of extractions were carried out using the same conditions, but at $55^{\circ} \mathrm{c}$. The results indicate that slight increase in extraction efficiency can be achieved using higher temperature.

\section{Using Ethane as the Extraction Solvent}

Ethane is an easily available and non contaminating solvent with readily achievable supercritical properties (305.4K and 48.8 bars). Marleny et al. (2001) used ethane as supercritical solvent for extraction of cocoa butter. The extraction of cocoa butter from cocoa beans were performed with ethane at 323.2 and $343.2 \mathrm{~K}$, pressures of $18.2,24.8$ and

28.3 MPaand ethane flow rate of $0.9 \mathrm{gm} \mathrm{min}^{-1}$. They found that extraction yields of cocoa butter using ethane, has an order of magnitude higher than obtained with $\mathrm{CO}_{2}$.

\section{Comparison of Extraction Efficiency between Carbon Dioxide and Ethane as Supercritical Solvent}

Salajegheh et al. (2013) investigated $\mathrm{SC}-\mathrm{CO}_{2}$ extraction of Cocoa Butter from Cocoa seed, keeping other conditions same for ethane and carbon dioxide ( $\mathrm{D}<\mathrm{I} \mathrm{mm}$, extraction time 8 hours) the difference between ethane and carbon dioxide was investigated once in constant pressure $(20 \mathrm{MPa})$ in different temperatures from 30 to $55^{\circ} \mathrm{C}$ and then in constant temperature $\left(50^{\circ} \mathrm{C}\right)$ from $5 \mathrm{MPa}$ to $20 \mathrm{MPa}$. As it is expected, in each case the extraction yield for ethane is much greater than carbon dioxide (more than 5 times) and in some cases $\left(55^{\circ} \mathrm{C}\right.$ and $20 \mathrm{MPa}$ the degree of magnitude is quite noticeable ( $53 \%$ for ethane but $5.2 \%$ for carbon dioxide).

\section{CONCLUSIONS}

It is concluded that the main process parameters affecting the supercritical extraction process are particle size, pressure, temperature and extraction time. As the pressure, temperature and extraction time increases, the extraction efficiency increases. But, decrease in particle size increases extraction efficiency. In some researches, it was unable to extract any more than $5 \%$ of the oil by traditional methods of supercritical extraction, using pure supercritical carbon dioxide. In order to achieve acceptable extraction efficiencies, a suitable co-solvent or an entirely different solvent is needed. Using ethanol as co solvent, would increase the efficiency of extraction up to 16 percent (for10 percent by weight ethanol) for a single pass, which isa significant improvement over use of pure $\mathrm{CO}_{2}$, Using pure ethane as the supercritical extraction solvent showed efficiencies as high as $53 \%$ extraction in a single pass, under optimum conditions in the range investigated (20 MPa pressure, $50{ }^{\circ} \mathrm{C}$ temperature and 8hours extraction time for particles with diameters less than $1 \mathrm{~mm}$ ). 
These results could be a good basis, as the first step of the industrial process of cocoa butter extraction from cocoa beans.

\section{REFERENCES}

1. Abbas, K.A., A. Mohamed, A.S. Abdulamir and Abas, H.A. 2008. A Review on Supercritical Fluid Extraction as New Analytical Method. American Journal of Biochemistry and Biotechnology. 4 (4): 345-353.

2. Catarina guedes et al., 2013. Supercritical fluid extraction of carotenoids and chlorophylls $a, b$ and $c$, from a wild strain of scenedesmus obliquus for use in food processing. Journal of food engineering, 116: 478-482.

3. Rahoma, S. Mohamed and G. Ali Mansoori, 2002. The Use of Supercritical Fluid Extraction Technology in Food Processing, Food Magazine, June 2002.

4. Mark., A. and M.C. Hugh, 1994. Supercritical Fluid Extraction Principles and Patrice $2^{\text {nd }}$ Edition, Butter worth Heinemann.

5. Perakis, C., V. Louli and K. Magoulas, 2005. Supercritical Fluid Extraction of Pepper Oil, Journal of Food Engineering, 71: 386-391.

6. Gerd Brunner, 2005. Technology and Application to Food Processing, Journal of Food Engineering 67: 21-33.

7. Vedaraman, N., C. Sriniv asakannan and G. Brunner, 2005. Experimental and Modeling Studies on Extraction of Cholesterol from Cow Brain Using Supercritical Carbon Dioxide Journal of Supercritical Fluids, 34: 27-34.

8. Gehrig, M., 1998. Extraction of Food Stuff with Carbon Dioxide: Present status and potential In M. Perrut and P. Subra (EdS), Proceedings of the 5 meeting on supercritical fluids, Nice, France, 2: 495-500.

9. Asep, E.K., S. Jinap and T.J. Tan, 2008. The effect of particle size, fermentation and roasting of cocoa nibs on supercritical fluid extraction of cocoa butter. journal of food, 85: 450-458.

10. Hung, T.V. and M.A. Unger, 1995. Cholestrol reduced egg yolk by supercritical fluid extraction, food Australia, 47(5): 227.

11. Weiz, Wu, Yucui, 2001. Mathematical modeling of extraction of egg yolk oil with supercritical CO2,Journal of supercritical fluids, 19: 149-15.

12. Maleny, D.A. Saldana, Carsten Zetel, Rahoma S. Mohamed and G. Brunner, 2002. Extraction of Mythylxanthines from Guana Seeds,Mate Leaves and Cocoa Beans using supercritical carbon dioxide and ethanol, Agric. Food Chem., 50: 4820-4826.

13. Shufen Li and Stanley Hartland, 1996. A new, industrial process for extracting cocoa butter and xanthines with supercritical carbon dioxide Journal of American Oil Chemists, 73(4): 423-429.

14. Uiram Kopcak, Rahoma Sadeg Mohamed, 2005. Caffeine solubility in supercritical carbon dioxide/co- solvent mixtures, The journal of supercritical fluids, 34: 209-214.

15. de Azevedo, A.B.A., Paulo MazzaferKieckbusch, R.S. Mohamed, S.A.B. Vieira de Melo and T.G. July/Sept, 2008. Extraction of caffeine, chlorogenic acids and th lipids from green coffee beans using supercritical carbon dioxide and co-solvents Braz. J. Chem. Eng., 25: 3.

16. de Azevedo, A.B.A., T.G. Kieckbush, A.K. Tashima, P. Mazzafera, S.A.B. Vieira de Melo and R.S. Mohamed, 2008. extraction of green coffee oil using supercritical carbon dioxide The Journal of Supercritical Fluids, 44(2): 186-192.

17. Zh. Li., X. Lu, Sh. Chen, X. Zhang, X. Yuanjing, Y. Wei, Y., F. Xia, An experimental and simulating study of supercritical CO2 extraction for pepper oil, Chem. Eng. Process. 45, 264-267 (2006).

18. Shi, J.; Yi, C.; Ye, X.; Xue, S.; Jiang, Y.; Ma, Y.; Liu, D. Effects of supercritical $\mathrm{CO}_{2}$ fluid parameters on chemical composition and yield of carotenoids extracted from pumpkin. LWT-. Food Sci. Technol 2010, 43, 39-44. 
19. Shi, X.; Wu, H.; Shi, J.; Xue, S.J.; Wang, D.; Wang, W.; Cheng, A.; Gong, Z.; Chen, X.; Wang, C. Effect of modifier on the composition and antioxidant activity of carotenoid extracts from pumpkin (Cucurbita maxima) by supercritical $\mathrm{CO}_{2}$. LWT-. Food Sci. Technol 2013, 51, 433-440.

20. Marleny, D.A., Saldaña and Rahoma S. Mohamed, 2001. Extraction of Cocoa Butter from Cocoa Beans using supercritical CO2 and Ethane, Fluid Phase Equilibria, 194-197: 885-894.

21. Nobre, BP., Palavra, AF., Pessoa, FLP., Mendes, RL. 2009. Supercritical CO2 extraction of trans-lycopene from Portuguese tomato industrial waste. Food Chem., 116 (3): 680-685.

22. Yi, C., Shi, J., Xue SJ., Jiang, Y., Li, D. 2009. Effects of supercritical fluid extraction parameters on lycopene yield and antioxidant activity. Food Chem., 113 (4): 1088-1094.

23. Lenucci, MS., Caccioppola, A., Durante, M., Serrone, L., Leonardo, R., Piro, G., Dollessandro, G. 2010. Optimisation of biological and physical parameters for lycopene supercritical CO2 extraction from ordinary and high-pigment tomato cultivars. J. Sci. Food Agri., 90 (10): 1709-1718.

24. Huang, W., Li, Z., Niu, H., Li, N., Zhang, J. 2008. Optimization of operating parameters for supercritical carbon dioxide extraction of lycopene by response surface methodology. J. Food Eng., 89 (3): 298-302.

25. Rozzi, NL., Singh, RK., Vierling, RA., Watkins, BA. 2002. Supercritical Fluid Extraction of Lycopene from Tomato Processing Byproducts. J. Agri. Food Chem., 50 (9): 2638-2643.

26. Baysal, T., Ersus, S., Starmans, DAJ. 2000. Supercritical CO2 Extraction of $\beta$-Carotene and Lycopene from Tomato Paste Waste. J. Agric. Food Chem., 48: 5507-5511.

27. Ciurlia, L., Bleve, M., Rescio, L. 2009. Supercritical carbon dioxide co-extraction of tomatoes (Lycopersicum esculentum L.) and hazelnuts (Corylus avellana L.): A new procedure in obtaining a source of natural lycopene. J. Supercrit. Fluid., 49 (3): 338-344.

28. Topal, U., Sasaki M., Goto M., Hayakawa, K. 2006. Extraction of Lycopene from Tomato Skin with Supercritical Carbon Dioxide: Effect of Operating Conditions and Solubility Analysis. J. Agri. Food Chem., 54 (15): 5604-5610.

29. Saldana MDA., Temelli F., Guigard SE., Tomberli B., Gray CG. 2010. Apparent solubility of lycopene and $\beta$-carotene in supercritical CO2, CO2+ethanol, and CO2+canola oil using dynamic extraction of tomatoes. J. Food Eng., 99 (1): 1-8.

30. [4] C. Perakis, V. Louli, K. Magoulas, Supercritical fluid extraction of black pepper oil, J. Food Eng. 71, 386-393 (2005).

31. D. Salajegheh, 1A. Vaziri and 2D. Bastani 2013. Supercritical Extraction of Cocoa Butter from Cocoa Seed, Using Pure Carbon Dioxide, Carbon Dioxide with Ethanol as Co-Solvent and Ethane. Middle-East Journal of Scientific Research. 13 (8): 1010-1015.

32. Egydio, JA., Moraes, AM., Rosa, PTV. 2010. Supercritical fluid extraction of lycopene from tomato juice and characterization of its antioxidation activity. J. Supercit. Fluid., 54 (2): 159-164.

33. Cadoni, E., De Giorgi, MR., Medda, E., Poma, G. 2000. Supercritical CO2 extraction of lycopene and $\beta$-carotene from ripe tomatoes. Dye. Pigment., 44: 27-32.

34. Sabio, E., Lozano, M., de Espinosa, VM., Mendes, RL., Pereira, AP., Palavra, AF., Coelho, JA. 2003. Lycopene and $\beta$ Carotene Extraction from Tomato Processing Waste Using Supercritical CO2. Ind. Eng. Chem. Res., 42 (25): 6641-6646.

35. Vagi, E., Simandi B., Vasarhelyine, KP., Daood, H., Kery, A., Doleschall, F., Nagy, B. 2007. Supercritical carbon dioxide extraction of carotenoids, tocopherols and sitosterols from industrial tomato by products. J. Supercrit. Fluid., 40 (2): 218-226. 
36. Topal, U., Sasaki M., Goto M., Hayakawa, K. 2006. Extraction of Lycopene from Tomato Skin with Supercritical Carbon Dioxide: Effect of Operating Conditions and Solubility Analysis. J. Agri. Food Chem., 54 (15): 5604-5610.

37. Ollanketo, M., Hartonen, K., Riekkola, ML., Holm, Y., Hiltunen, R. 2001. Supercritical carbon dioxide extraction of lycopene in tomato skins. Eur. Food Res.Technol., 212 (5): 561-565.

38. Rozzi, NL., Singh, RK., Vierling, RA., Watkins, BA. 2002. Supercritical Fluid Extraction of Lycopene from Tomato Processing Byproducts. J. Agri. Food Chem., 50 (9): 2638-2643.

39. Kassama, LS., Shi, J., Mittal, GS. 2008. Optimization of supercritical fluid extraction of lycopene from tomato skin with cental composite rotatable design model. Sep. Purif. Technol., 60 (3): 278-284.

40. Baysal, T., Ersus, S., Starmans, DAJ. 2000. Supercritical CO2 Extraction of $\beta$-Carotene and Lycopene from Tomato Paste Waste. J. Agric. Food Chem., 48: 5507-5511.

41. Saldana MDA., Temelli F., Guigard SE., Tomberli B., Gray CG. 2010. Apparent solubility of lycopene and $\beta$-carotene in supercritical CO2, CO2+ethanol, and CO2+canola oil using dynamic extraction of tomatoes. J. Food Eng., 99 (1): 1-8.

42. Shi, J., Yi C., Xue SJ., Jiang Y., Ma Y., Li D. 2009a. Effects of modifiers on the profile of lycopene extracted from tomato skins by supercritical CO2. J. Food Eng., 93 (4): 431-436.

43. Cadoni, E., De Giorgi, MR., Medda, E., Poma, G. 2000. Supercritical CO2 extraction of lycopene and $\beta$-carotene from ripe tomatoes. Dye. Pigment., 44: 27-32.

44. Ciurlia, L., Bleve, M., Rescio, L. 2009. Supercritical carbon dioxide co-extraction of tomatoes (Lycopersicum esculentum L.) and hazelnuts (Corylus avellana L.): A new procedure in obtaining a source of natural lycopene. J. Supercrit. Fluid., 49 (3): 338-344.

45. Ollanketo, M., Hartonen, K., Riekkola, ML., Holm, Y., Hiltunen, R. 2001. Supercritical carbon dioxide extraction of lycopene in tomato skins. Eur. Food Res.Technol., 212 (5): 561-565.

46. Published in Supercritical Fluid Extraction In: Reedijk, J. (Ed.) Elsevier Reference Module in Chemistry,. Waltham, MA: Elsevier. 30-Jun-14 doi: 10.1016/B978-0-12-409547-2.10753-X.

47. Emily Li Chin Cheah, Lai Wah Chan, Paul Wan Sia Heng,. 2006. Supercritical Carbon Dioxide and Its Application in the Extractionof Active Principles from Plant Materials. Asain Journal of Pharmaceutical Science, 1: 59-71.

48. Micic.v et al., 2011. Supercritical fluid extraction with carbon dioxide at different pressures. Contemporary Materials 2 (1): 84-87.

49. Sapkale.G. N., Patil, S. M., Surwase, U. S. And Bhatbhage, P. K. 2010. A Review on Supercritical Fluid Extraction. Int. J. Chem. Sci., 8(2): 729-743. 